\title{
Microstructures and erosion-corrosion behavior of Fe-B alloy containing chromium and nickel
}

\author{
*Da-wei Yi', Yu-pu Shi', Han-guang Fu', Jin Chen', Chong Li \\ 1. College of Materials Science and Engineering, Xi'an University of Science and Technology, Xi'an 710054, China; \\ 2. College of Materials Science and Engineering, Beijing University of Technology, Beijing 100124, China;
}

\begin{abstract}
The Fe-B alloy containing chromium and nickel was prepared, and the microstructure and erosioncorrosion behavior of the alloy were investigated by means of scanning electron microscopy, energy dispersive $\mathrm{X}$-ray spectrometry, X-ray diffraction analysis, Leica digital image analysis, a hardness tester and an erosioncorrosion tester. Cr28 white cast iron was used for comparison. Results show that the microstructures of both as-cast and heat-treated Fe-B alloys consist of austenite and borocarbide. The nickel and chromium elements are mainly distributed over the matrix and borocarbide, respectively. The hardness of the austenite matrix and the Rockwell hardness of heat-treated Fe-B alloy are higher than those of as-cast Fe-B alloy. In the erosioncorrosion test of the slurry, the erosion-corrosion weight loss of Fe-B alloy is lower than that of $\mathrm{Cr} 28$ white cast iron, indicating the Fe-B alloy displays higher erosion-corrosion resistance.
\end{abstract}

Key words: microstructure; borocarbide; chromium; nickel; erosion-corrosion

CLC numbers: TG143.9 Document code: $\mathrm{A}$

Article ID: 1672-6421(2019)05-307-06

$\mathrm{H}$ igh chromium cast irons contain many eutectic carbides which have high hardness and therefore these alloys possess an excellent wear resistance ${ }^{[1-3]}$. They are not only used in two-body and three-body wear conditions, but also in corrosion wear conditions ${ }^{[4-6]}$. Investigations have discovered that severe inter-phase corrosion occurs in high chromium cast iron in strong acidic media. Inter-phase corrosion has a detrimental effect on the erosion and corrosion resistance of high chromium cast iron, which can more severely deplete the matrix and expose the carbides. Under the action of slurry erosion and corrosion, without the support of the matrix, the carbides can be easily broken, which will result in a severe decline in the life of high chromium cast iron ${ }^{[7]}$. Therefore, the development of new materials working in erosion and corrosion conditions is of high technical relevance.

The research on high boron cast alloy is of wide interest by scholars ${ }^{[8-12]}$. The hardness of boride is higher than that of carbide, which provides the possibility to replace carbide with boride in white cast iron ${ }^{[13]}$. Fu et al. ${ }^{[10]}$ studied microstructure variation in B-bearing austenitic stainless steel under different heat treatment

*Da-wei Yi

Male, Ph.D, Associate Professor. His main research interest is focused on wear resistant materials.

E-mail: Yidawei19820608@163.com

Received: 2019-01-11; Accepted: 2019-06-20 conditions. The results revealed that the austenitizing temperature exceeding $950{ }^{\circ} \mathrm{C}$ can promote the breaking of the borocarbide networks and appearance of isolated borocarbides. Zhang et al. ${ }^{[14]}$ studied the effects of chromium addition on the abrasion resistance of $\mathrm{Fe}-\mathrm{B}$ cast alloy. The results revealed that the wear resistance of Fe-B cast alloy had been improved by adding chromium element. Ma et al. ${ }^{[15]}$ studied the effects of chromium concentration on microstructure and properties of $\mathrm{Fe}$ $3.5 \mathrm{~B}$ alloys. The results showed that when the chromium concentration exceeded $8 \mathrm{wt} . \%$, the morphology of boride became dispersed. Owing to the introduction of chromium atoms into the $\mathrm{Fe}_{2} \mathrm{~B}$, the fracture toughness of boride was improved. It is also found that nickel can improve the corrosion resistance of steel ${ }^{[16]}$.

In the present research, the microstructures and erosioncorrosion behavior of Fe-B alloy containing chromium and nickel have been investigated. Moreover, the erosioncorrosion mechanism for the test alloys is discussed.

\section{Experimental procedures}

\subsection{Sample preparation}

A $10 \mathrm{~kg}$ capacity medium-frequency induction furnace was used to melt the test alloys. Initial charge materials included pure iron and steel scrap, which were melted in the furnace. And then, $\mathrm{Fe}-58.2 \mathrm{wt} . \% \mathrm{Cr}$ alloy, $\mathrm{Fe}-$ 72.6wt.\% Si alloy, Fe-62.5wt.\% Mn alloy and nickel 
board were put into the molten alloy. When the temperature of the molten alloy increased to $1,630{ }^{\circ} \mathrm{C}, \mathrm{Fe}-15.6 \mathrm{wt} . \% \mathrm{~B}$ alloy was put into the furnace. The molten alloy was deoxidized with pure aluminum and then poured into a ladle. Finally, the molten alloy was poured into a sand mould at $1,490{ }^{\circ} \mathrm{C}$. The test specimens were heated to $1,100^{\circ} \mathrm{C}$ for $2 \mathrm{~h}$ using a box-type resistance furnace and then quenched in water. The chemical compositions of the test alloy determined by optical emission spectroscopy are shown in Table 1.

Table 1: Chemical compositions of Fe-B alloy containing chromium and nickel (wt.\%)

\begin{tabular}{ccccccccc} 
C & B & Cr & Ni & Si & Mn & S & P & Fe \\
\hline 0.13 & 1.61 & 18.31 & 8.86 & 0.62 & 0.68 & 0.02 & 0.03 & Bal.
\end{tabular}

\subsection{Microstructure examination}

The geometries of the samples are shown in Fig. 1. Sample A, in Fig. 1(a), with dimension $20 \times 20 \times 10 \mathrm{~mm}^{3}$ was used to carry out the metallographic analysis. Before metallographic analysis, the polished surface of sample A was etched in a mixture of $5 \mathrm{ml}$

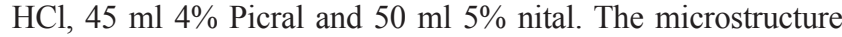
was characterized using a Tescan Vegaiixmu scanning electron microscope (SEM) equipped with an energy dispersive X-ray spectrometry (EDS, OXFORD 7718). The phase constitutions were identified using a D/MAX-2400 diffractometer with copper $\mathrm{K} \alpha$ radiation at $40 \mathrm{kV}$ and $30 \mathrm{~mA}$ as $\mathrm{X}$-ray source. The specimens were scanned in a $2 \theta$ range from 10 to $90^{\circ}$ with an increment of $0.02^{\circ}$ per step. (a)

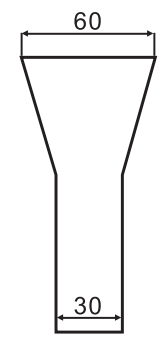

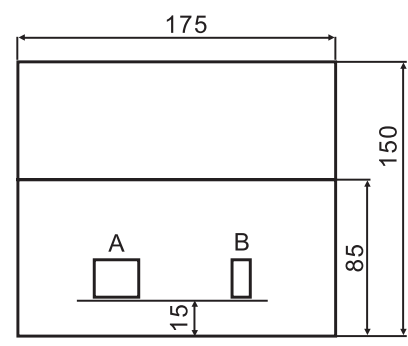

(b)

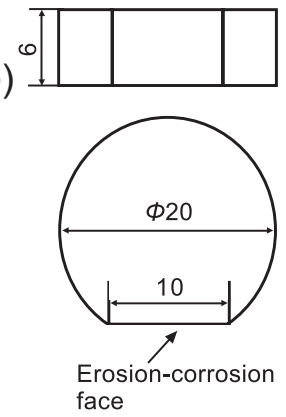

Fig. 1: Schematics of casting block (a) and erosion-corrosion sample (b) (unit: $\mathrm{mm}$ )

Leica digital image analyzer was used to analyze the borocarbide area fraction $(F)$. Twenty images of the specimen at the magnification of 200 times were randomly selected and processed to measure $F$. The test result was the average of 20 values. The borocarbide area fraction $(F)$ in one image was given by the following equation ${ }^{[16]}$ :

$$
F=\frac{A_{b}}{A}
$$

where $A_{\mathrm{b}}$ was the area of total borocarbides, and $A$ was the area of one image.

\subsection{Hardness tests}

The Rockwell hardness of the alloy was tested on a HRS-150 hardness tester under a load of 1,470 N. The average value of ten measured values was considered to be the final result. Based on ASTM standard E384-08 ${ }^{[17]}$, the microindentation hardness measurement was completed by using a HXD-1000TMC tester under loads of $0.49 \mathrm{~N}$ and $0.98 \mathrm{~N}$, respectively, for the matrix and borocarbide, with the samples maintained for $10 \mathrm{~s}$ under the full test force. The mean of twenty measurements was considered to be the test result.

\subsection{Erosion-corrosion tests}

Erosion-corrosion behavior of Fe-B alloy in slurry was studied using an erosion-corrosion tester. Cr28 white cast iron (2.51C-28.13Cr-2.21Mo, wt.\%, the hardness is $61.2 \pm 0.8 \mathrm{HRC}$ ) was chosen as the contrast material. The structure of the erosioncorrosion tester is shown in Fig. 2. The geometry of the erosioncorrosion sample [sample B in Fig. 1(a)] is shown in Fig. 1(b).
Before the erosion-corrosion test, the erosion-corrosion surface of sample B must be polished. The mixing wheel in Fig. 2 was rotated at 1,200 $\mathrm{r} \cdot \mathrm{min}^{-1}$ and $1,700 \mathrm{r} \cdot \mathrm{min}^{-1}$, respectively. The distance between the mixing wheel center and the erosioncorrosion sample (see " $L$ " in Fig. 2) was $80 \mathrm{~mm}$. The erosioncorrosion slurry was a mixture of $8,000 \mathrm{ml} 2.4 \%$ sulfuric acid solution and $3 \mathrm{~kg}$ quartz sand $\left(\mathrm{SiO}_{2}, 900-1,100 \mathrm{HV}^{[18]}\right)$. During the test, the temperature of the slurry was controlled at $20 \pm 1{ }^{\circ} \mathrm{C}$ by cooling water. The grain size of the quartz sand was $0.63 \pm 0.11$ $\mathrm{mm}$. The impingement angles (Fig. 2) for the erosion-corrosion

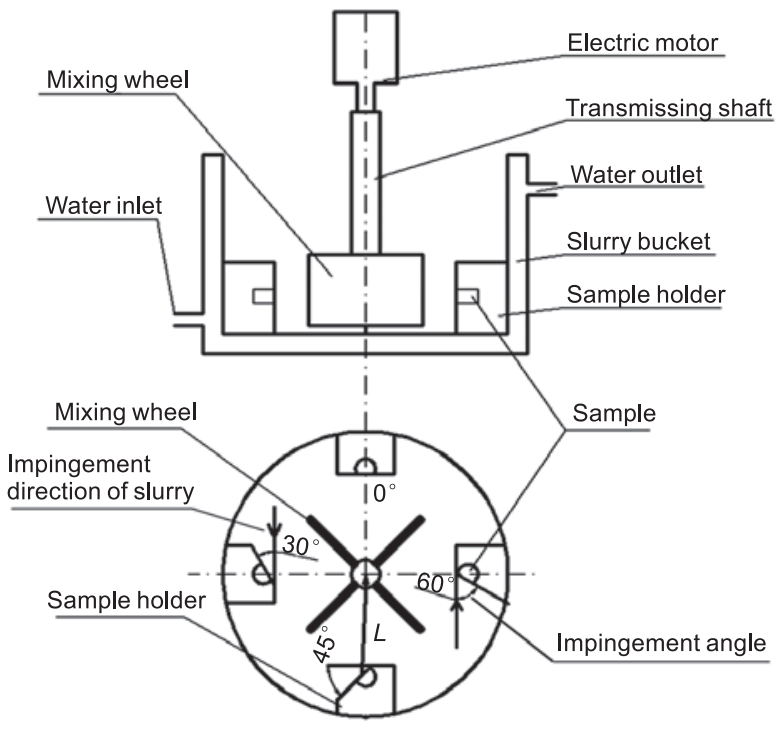

Fig. 2: Schematic diagram of erosion-corrosion testing machine 
specimen were $0^{\circ}, 30^{\circ}, 45^{\circ}$ and $60^{\circ}$, respectively. The time of one erosion-corrosion test for four specimens was $180 \mathrm{~min}$. After the test, the weight loss of the specimen was measured by an electronic balance, with an accuracy of $0.1 \mathrm{mg}$. The average value of three measurements was considered to be the test weight loss result.

\section{Results and discussion}

\subsection{Microstructure}

The microstructures of Fe-B alloy with nickel and chromium elements consist of the eutectic borocarbide and matrix. The XRD result (Fig. 3) reveals that the eutectic borocarbide and matrix are the $\mathrm{M}_{2}(\mathrm{~B}, \mathrm{C})$ and the austenite $(\gamma-\mathrm{Fe})$, respectively. $\mathrm{M}$ represents that chromium and iron elements exist in the borocarbide ${ }^{[9]}$. The morphology of $\mathrm{M}_{2}(\mathrm{~B}, \mathrm{C})$ borocarbide is continuous networks (Fig. 4). Figure 5 shows that the microstructures of the heat-treated Fe-B alloy are also

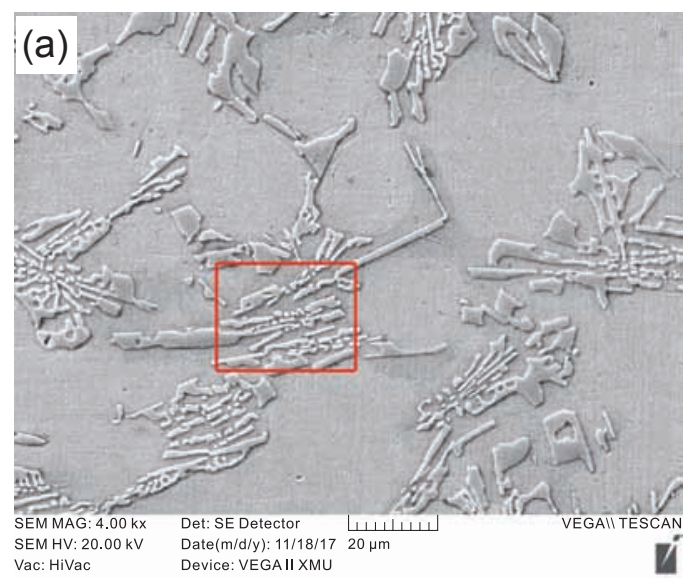

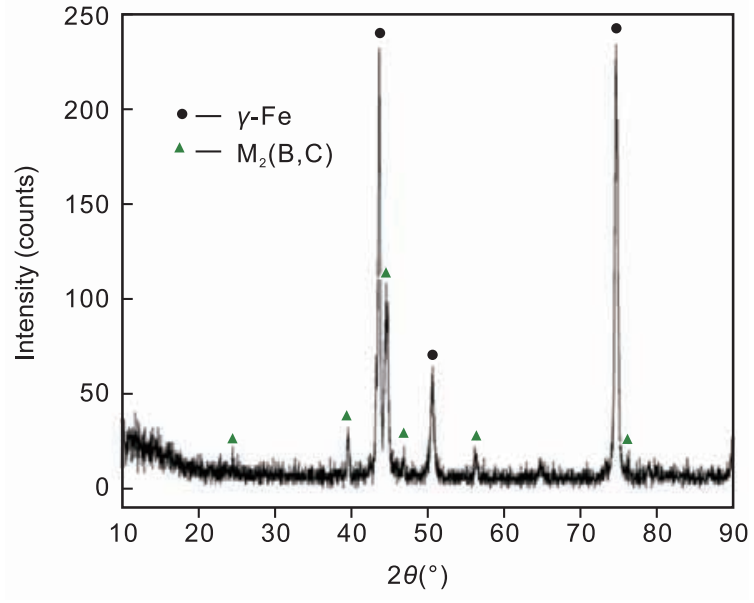

Fig. 3: X-ray diffraction spectrum of as-cast Fe-B alloy

composed of the eutectic borocarbide and austenite matrix. The morphology of the network borocarbide in the heat-treated Fe-B alloy is similar to that in the as-cast Fe-B alloy.

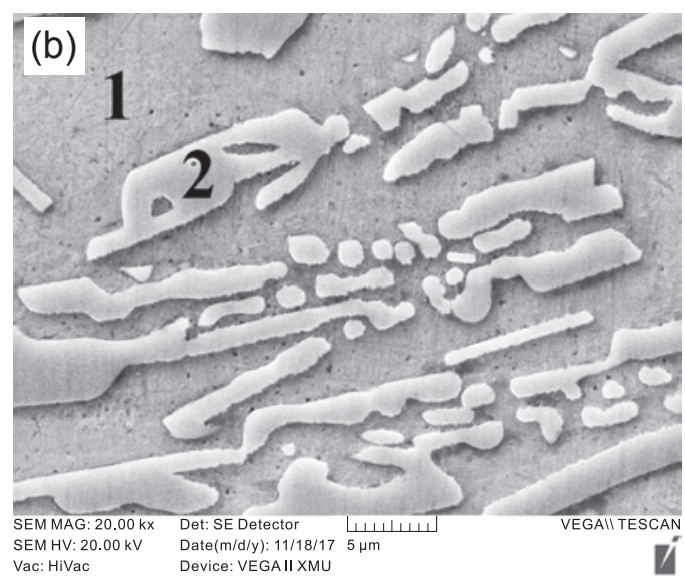

Fig. 4: Solidification microstructures of as-cast Fe-B alloy: 1- austenite; 2 - borocarbide $\left[M_{2}(B, C)\right]$
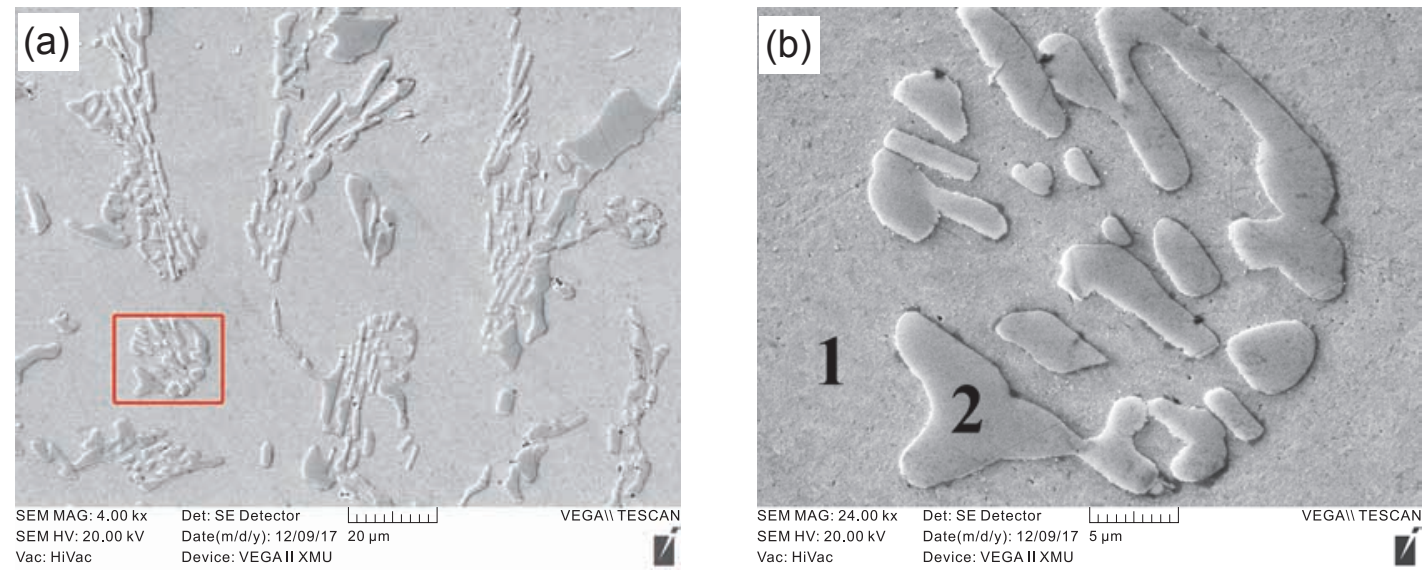

Fig. 5: Microstructures of heat-treated Fe-B alloy: 1 - austenite; 2 - borocarbide $\left[M_{2}(B, C)\right]$

Figure 6 shows the distributions of nickel and chromium elements in the as-cast Fe-B alloy analyzed by EDS. It can be found that chromium elements are mainly located in the $\mathrm{M}_{2}$ (B,C) borocarbide [Fig. 6(b)], and some chromium elements are located in the matrix; nickel elements are principally located in the austenite matrix [Fig. 6(c)], and a small quantity of nickel elements are located in the borocarbide.

\subsection{Hardness}

The hardness values of austenite and borocarbide are shown in Table 2. In heat-treated Fe-B alloy, the microindentation hardness of borocarbide is close to that in as-cast alloy, while 


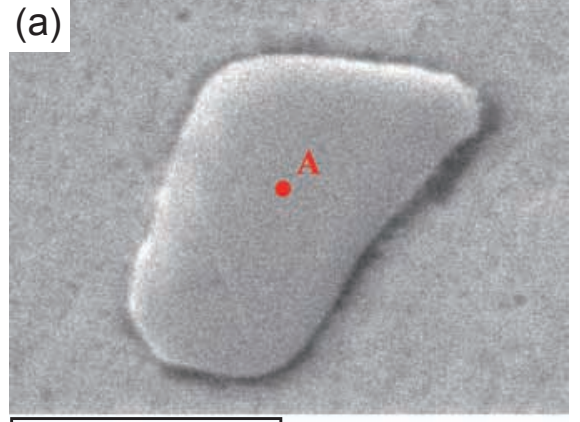

$6 \mu \mathrm{m}$

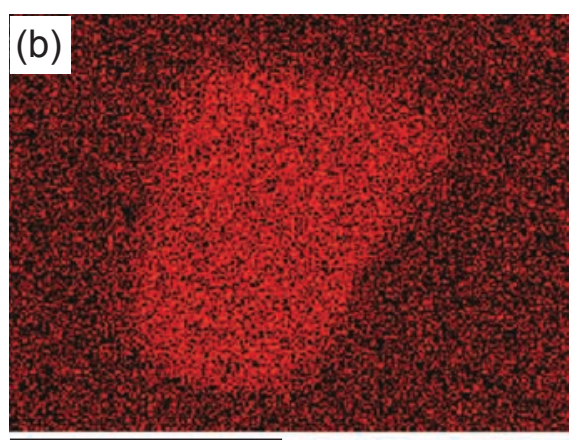

$6 \mu \mathrm{m}$

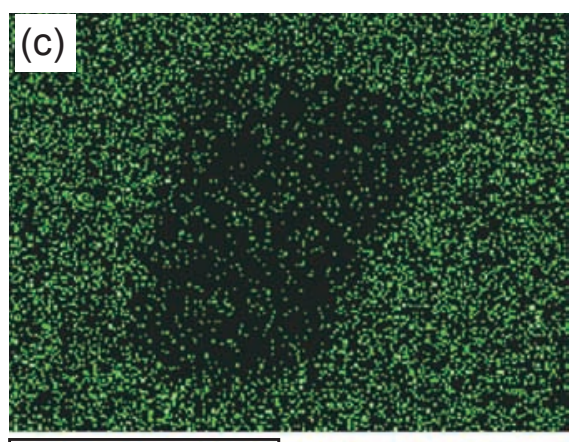

$6 \mu \mathrm{m}$

Fig. 6: SEM (a) and distributions of chromium (b) and nickel (c) elements around point A by EDS

the borocarbide area fraction is lower than that in as-cast alloy (Table 2). Two reasons may exist: firstly, the borocarbides have excellent thermal stability and do not decompose at $1,100{ }^{\circ} \mathrm{C}$; secondly, when the austenitizing temperature is higher than $1,050{ }^{\circ} \mathrm{C}$, parts of the borocarbide networks are dissolved into the matrix ${ }^{[10]}$. Compared with as-cast Fe-B alloy, in heat-treated Fe-B alloy, the solution of boron element in the metallic matrix promotes the strengthening of the austenite matrix, and leads to the increase of the microindentation hardness of the austenite matrix and the Rockwell hardness of heat-treated Fe-B alloy.

Table 2: Hardness of austenite matrix and borocarbide for as-cast and heat-treated Fe-B alloy

$\begin{array}{cccc}\text { Specimens } & \text { Parameters } & \text { Values } & \text { Deviation } \\ & \text { Austenite (HV) } & 208 & 9 \\ \text { As-cast } & \text { Borocarbide (HV) } & 1564 & 16 \\ & \text { F } & 12.91 & 0.18 \\ & \text { R } & 22.3 & 0.4 \\ \text { Heat-treated } & \text { Bustenite (HV) } & 252 & 8 \\ & \text { Borocarbide (HV) } & 1556 & 18 \\ & \text { F } & 11.43 & 0.17 \\ & \text { R } & 25.8 & 0.3\end{array}$

Note: $\mathrm{F}$ refers to the borocarbide area fraction (\%) and $\mathrm{R}$ corresponds to the Rockwell hardness (HRC).

\subsection{Erosion-corrosion behavior of Fe-B alloy}

The erosion-corrosion weight losses of the $\mathrm{Cr} 28$ white cast iron $(2.51 \mathrm{C}-28.13 \mathrm{Cr}-2.21 \mathrm{Mo}$, wt.\%, the hardness is $61.2 \pm 0.8$ $\mathrm{HRC}$ ) and Fe-B alloy are shown in Fig. 7. The erosion-corrosion surface morphologies of $\mathrm{Cr} 28$ and Fe-B alloy specimens are shown in Figs. 8, 9 and 10.

The hardness (Hu1) of the $\mathrm{M}_{2}(\mathrm{~B}, \mathrm{C})$ borocarbide is between 1,540 HV and 1,590 HV (100 g). The hardness (Ha) of the quartz sand $\left(\mathrm{SiO}_{2}\right)$ abrasive is between $900 \mathrm{HV}$ and $1,100 \mathrm{HV}^{[18]}$, the ratio of $\mathrm{Hu} 1$ to $\mathrm{Ha}$ is greater than 1 , and the quartz sand is considered to be the soft abrasive ${ }^{[19]}$. The borocarbide cannot be "cut" by soft abrasive particles $\left(\mathrm{SiO}_{2}\right)$, while the $\mathrm{SiO}_{2}$ abrasive

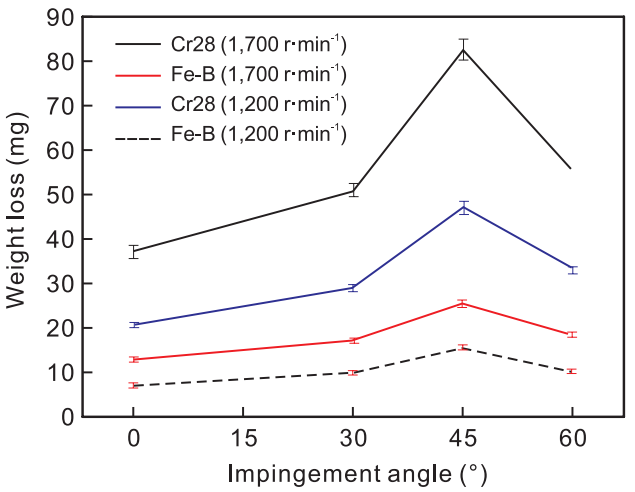

Fig. 7: Erosion-corrosion weight loss graph of $\mathrm{Cr} 28$ white cast iron and Fe-B alloy under different mixing wheel rotating speeds and impingement angles

can break the borocarbide by impact. The hardness (Hu2) of the austenite matrix is lower than $270 \mathrm{HV}(50 \mathrm{~g})$, the ratio of $\mathrm{Hu} 2$ to $\mathrm{Ha}$ is lower than 0.8 , and the quartz sand is considered to be the hard abrasive. The austenite matrix must be scraped by hard abrasive particles. Based on the above calculation method, compared with the matrix (670-710 HV) and carbide (1,480$1,540 \mathrm{HV}$ ) in $\mathrm{Cr} 28$ white cast iron, the quartz sand abrasive can be classified as hard abrasive and soft abrasive, respectively. So, the abrasive particles can scrape the matrix, and the impact between abrasive and carbide can cause the carbide to break.

Some scraping traces [the blue arrows in Fig. 8(b)] and pits [the red arrows in Fig. 8(a)] appear in the erosion-corrosion surface of Fe-B alloy specimen (under the rotating speed of 1,200 $r \cdot m^{-1}$, impingement angle of $45^{\circ}$ ). When the slurry erodes and corrodes the surface of the specimen, the quartz sand can scrape the matrix and promote the appearance of scrape trace. The corrosion and scraping destructions of the matrix result in the exposure of the borocarbide. The exposed borocarbide must be broken by the impact of the quartz sand, and pits [Fig. 8(b)] are left in the erosion-corrosion surface.

Figure 7 shows that the higher rotating speed of the mixing wheel results in higher erosion-corrosion weight loss for both Fe-B alloy and Cr28 white cast iron. It can also be seen that, for Fe-B alloy, the borocarbide pits in Fig. 9 (b) (red arrows) are greater in number and size than those in Fig. 8 (a) (red arrows), which is consistent with Fig. 7. This is because the higher rotating speed of the mixing wheel can increase the impact 

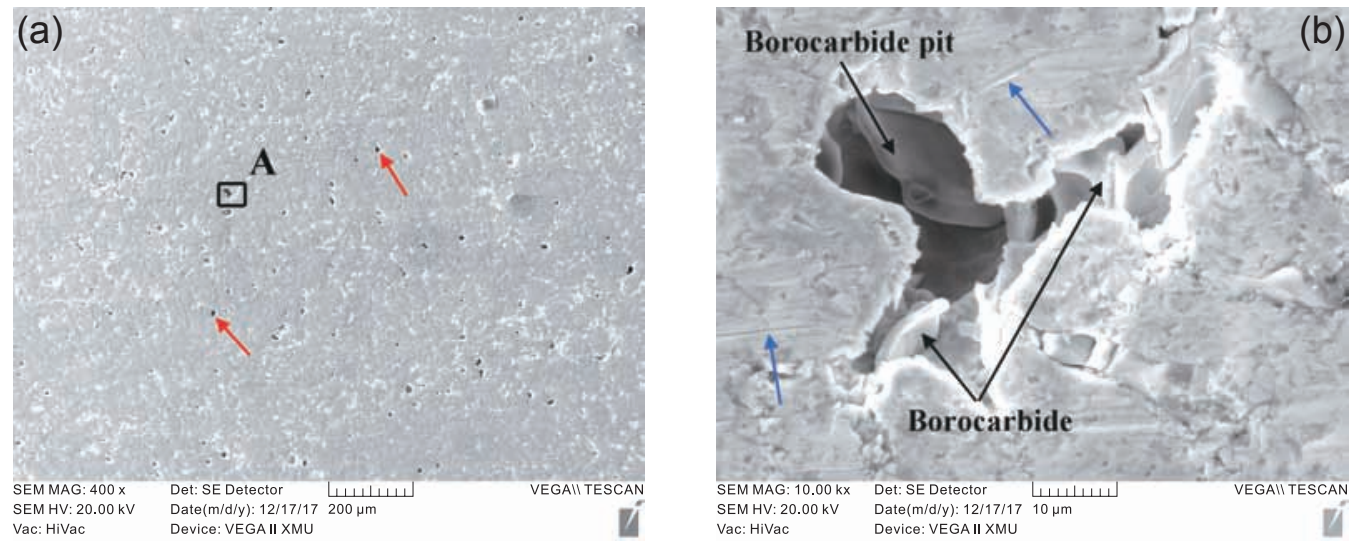

Fig. 8: Erosion-corrosion surface SEM of Fe-B alloy specimen under test condition of impingement angle $45^{\circ}$, and rotating speed $1,200 \mathrm{r} \cdot \mathrm{min}^{-1}$, (b) showing the magnified morphology of area $A$
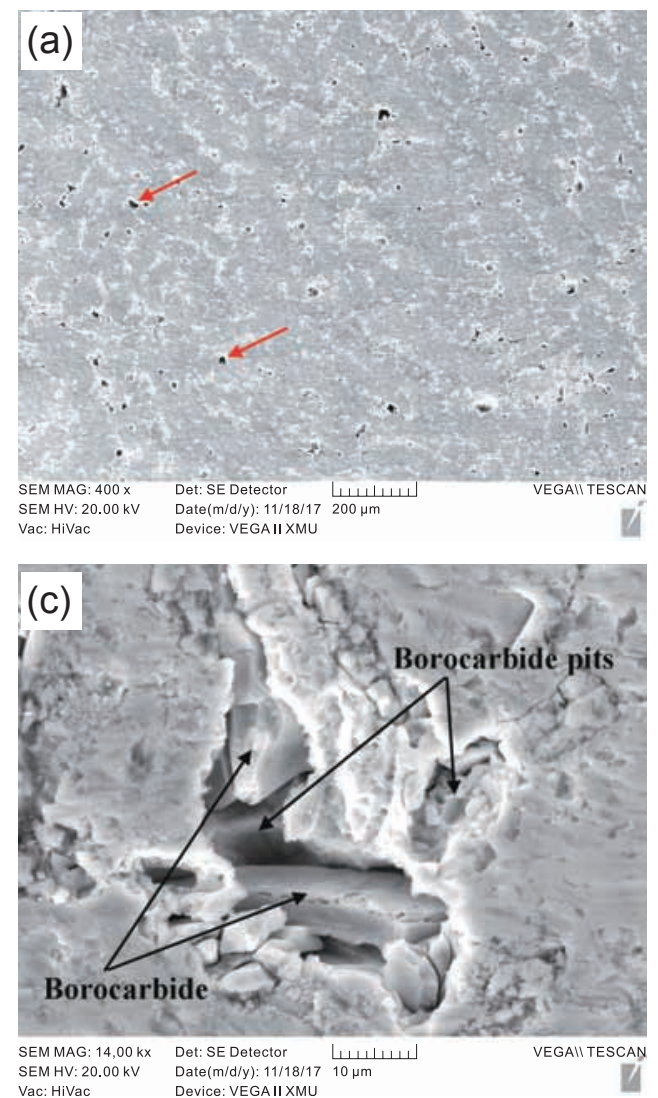
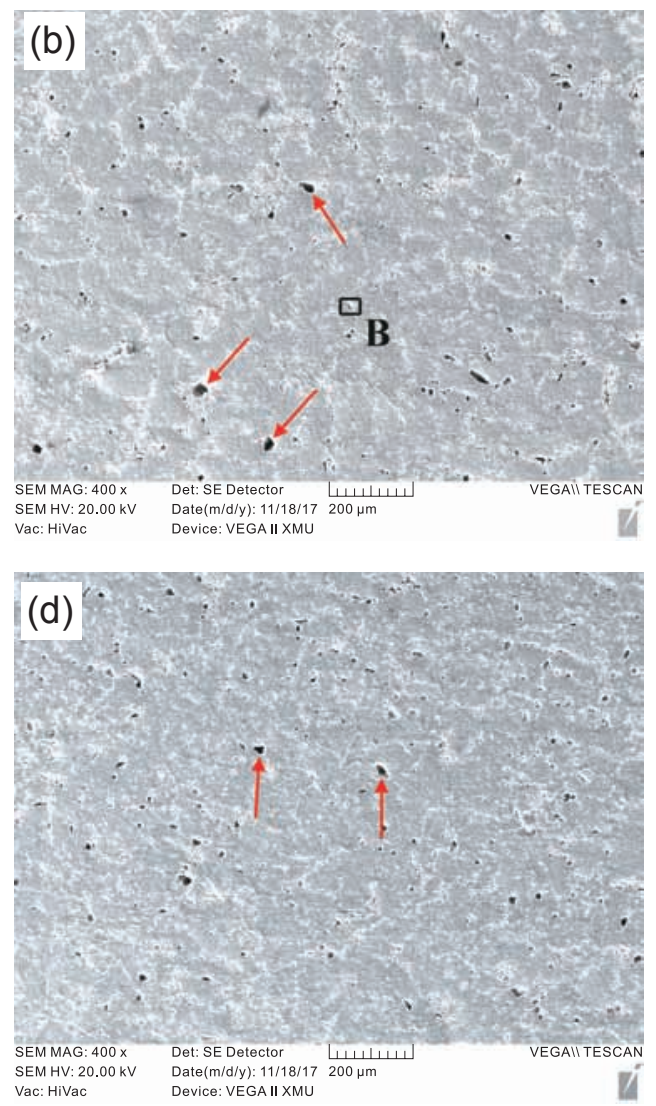

Fig. 9: SEM graphs of erosion-corrosion surfaces of Fe-B alloy specimens under a rotating speed of 1,700 $\mathrm{r} \cdot \mathrm{min}^{-1}$ and impingement angles of $0^{\circ}(\mathrm{a}), 45^{\circ}(\mathrm{b})$ and $60^{\circ}$ (d), respectively; (c) is the morphology of area $B$

velocity of the slurry. The slurry with a higher impact velocity exacerbates the matrix damage and borocarbide breakage, which results in a higher erosion-corrosion weight loss.

Compared with $0^{\circ}, 30^{\circ}$ and $60^{\circ}$ impingement angles, when the impingement angle is $45^{\circ}$, both Fe-B alloy specimen and $\mathrm{Cr} 28$ white cast iron specimen have the higher erosion-corrosion weight loss (Fig. 7). Corresponding to the above results, for Fe-B alloy, compared with $0^{\circ}$ and $60^{\circ}$ impingement angles [red arrows in Figs. 9(a) and (d)], there are more broken borocarbides and larger borocarbide pits in the erosion-corrosion surface under $45^{\circ}$ impingement angle test condition [the red arrows in Fig. 9(b)]. The above results prove a conclusion: for $45^{\circ}$ impingement angle test condition, the slurry can erode and corrode specimen more strongly than the other impingement angles.

Generally, for all the test conditions, the erosion-corrosion weight losses of Fe-B alloy specimens are lower than those of Cr28 white cast iron specimens (Fig. 7). In the erosion-corrosion surface of $\mathrm{Cr} 28$ white cast iron specimen (the rotating speed of the mixing wheel is $1,700 \mathrm{r} \cdot \mathrm{min}^{-1}$, and the impingement angle is $45^{\circ}$ ), the matrix is severely eroded and corroded by the slurry, many carbides are severely broken, and some large carbide pits appear [the red arrows in Fig. 10(a)]. In contrast, in the erosioncorrosion surface of Fe-B alloy specimen, the borocarbides are slightly broken, and the borocarbide pits are also small [the red arrows in Fig. 9(b)]. Therefore, the Fe-B alloy exhibits excellent erosion-corrosion resistance property. 

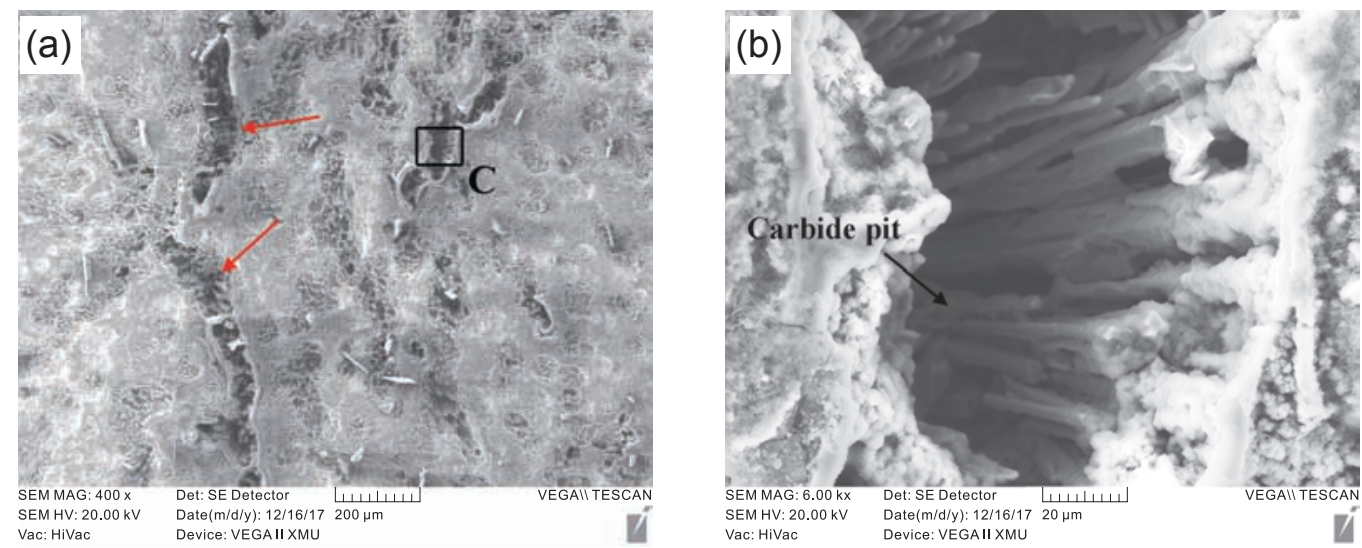

Fig. 10: (a) SEM graphs of erosion-corrosion surface of Cr28 white cast iron specimen, and (b) morphology of area $C$ under erosion-corrosion test condition of impingement angle of $45^{\circ}$ and rotating speed of 1,700 $r \cdot \min ^{-1}$

\section{Conclusions}

(1) The microstructures of as-cast Fe-B alloy are composed of austenite and $\mathrm{M}_{2}(\mathrm{~B}, \mathrm{C})$ borocarbide. The chromium and nickel elements are mainly located over the borocarbide and matrix, respectively.

(2) The microstructure of heat-treated Fe-B alloy also consists of the austenite and $\mathrm{M}_{2}(\mathrm{~B}, \mathrm{C})$ borocarbide. Compared with ascast Fe-B alloy, the hardness of the austenite matrix and the Rockwell hardness of heat-treated Fe-B alloy are higher.

(3) Under the erosion-corrosion of the slurry, for Fe-B alloy, the matrix is scraped, and the borocarbides are broken. In every test condition, the erosion-corrosion weight loss of $\mathrm{Fe}-\mathrm{B}$ alloy is lower than that of $\mathrm{Cr} 28$ white cast iron, and the Fe-B alloy exhibits higher erosion-corrosion resistance property.

\section{References}

[1] Arikan M M, Cimennoglu H, Kayali E S. The effect of titanium on the abrasion resistance of $15 \mathrm{Cr}-3 \mathrm{Mo}$ white cast iron. Wear, 2001, (247): 231-235.

[2] Cetinkaya C. An investigation of the wear behaviours of white cast irons under different compositions. Materials Design, 2006, 27: 437-445.

[3] Pintaude G, Tschiptschin A P, Tanaka D K, et al. The particle size effect on abrasive wear of high-chromium white cast iron mill balls. Wear, 2001, 250(1): 66-70.

[4] Pearce J T H. Structure and wear performance of abrasion resistant chromium white cast irons. Transactions of the American Fisheries Society, 1984, 126: 599-622.

[5] Dogan O N, Hawk J A, Laird II G. Solidification structure and abrasion resistance of high chromium white irons. Metallurgical and Materials Transactions A, 1997, 28A(6): 1315-1328.

[6] Zhang Anfeng, Xing Jiandong, Gao Yi Min, et al. Mechanism and electrochemical behavior of inter-phase corrosion of chromium white cast irons. Acta Metallurgica Sinica, 2000, 36(7): 765769. (In Chinese)
[7] Zhang Anfeng, Xing Jiandong. A quantitative investigation on the dynamic inter-phase corrosion of chromium white cast irons. Acta Metallurgica Sinica, 2001, 37(1): 77-81. (In Chinese)

[8] Liu Z L, Li Y X, Chen X, et al. Microstructure and mechanical properties of high boron white cast iron. Materials Science and Engineering A, 2008, 486: 112-116.

[9] Fu H G, Li Z H, Jiang J Q, et al. Solidification structure in a cast B-bearing stainless steel. Materials Letters, 2007, 61: 45044507.

[10] Fu H G, Li Z H, Lei Y Q, et al. Structural variations in heat treated B-bearing stainless steel. Materials \& design, 2009, 30: 885-891.

[11] Peev K, Radulovic M, Fiset M. Modification of Fe-Cr-C alloys using mischmetal. Journal of Materials Science Letters, 1994, 13: 112-114.

[12] Yi Y L, Xing J D, Wan M J, et al. Effect of Cu on microstructure, crystallography and mechanical properties in Fe-B-C-Cu alloys. Materials Science and Engineering A, 2017, 708: 274-284.

[13] Guo C Q, Wang C D, Liu X P, et al. Effect of variable heat treatment modes on microstructures of $\mathrm{Fe}-\mathrm{Cr}-\mathrm{B}$ cast iron alloy. China Foundry, 2008, 5(1): 28-31.

[14] Zhang J J, Gao Y M, Xing J D. Effects of chromium addition on microstructure and abrasion resistance of $\mathrm{Fe}-\mathrm{B}$ cast alloy. Tribology Letters, 2011, 44: 31-39.

[15] Ma S Q, Xing J D, Liu G F, et al. Effect of chromium concentration on microstructure and properties of $\mathrm{Fe}-3.5 \mathrm{~B}$ alloy. Materials Science and Engineering A, 2010, 527(26): 6800-6808.

[16] Yi D W, Xing J D, Ma S Q, et al. Three-body abrasive wear behavior of low carbon Fe-B cast alloy and its microstructures under different casting process. Tribology Letters, 2011, 42: 6777.

[17] American Society for Testing and Materials, ASTM E384-08, Standard test method for microindentation hardness of materials, American Society for Testing and Materials, West Conshohocken, PA, 2008.

[18] Li Y F, Gao Y M. Three-body abrasive wear behavior of CC/ high-Cr WCl composite and its interfacial characteristics. Wear, 2010, 268: 511-518.

[19] Richardson R C D. The wear of metals by hard abrasives. Wear, 1967, 10: 291-309. 